\title{
HUBUNGAN KARAKTERISTIK INDIVIDU, BUDAYA ORGANISASI, DAN ORGANIZATION CITIZENSHIP BEHAVIOR DENGAN KINERJA ORGANISASI
}

\author{
Arie Ambarwati \\ Universitas Hang Tuah Surabaya, Surabaya, Indonesia, email: arie.ambarwati@ hangtuah.ac.id
}

\begin{abstract}
Organizational performance / company been an research will is always interesting to talk about in the business world or the management of organization. Several factors and variables affecting the performance of the organization. This study attempts to analyze the individual characteristics, relationship the culture of the organization citizenship behavior (OCB) with performance / organization company. Quantitative research methodology used is explanatory using 35 respondents an employee in the services sector financial Surabaya city consultation.

The research suggests that there is a directly or indirectly between individual characteristics, cultural organization, organization citizenship behavior (OCB) with organizational performance. The analysis showed that only cultural organizations and organization citizenship behavior $(O C B)$ giving immediate and significant relationship with, organizational performance while individual characteristics not giving the correlations directly with. organizational performance.
\end{abstract}

Keywords: Individual characteristics, Organization Culture, Organization Citizenship Behavior, Organizational performance.

\begin{abstract}
Abstrak
Kinerja organisasi/perusahaan merupakan bahan penelitian yang akan selalu menarik untuk dibicarakan dalam dunia bisnis atau pengelolaan organisasi. Beberapa faktor dan variabel yang mempengaruhi kinerja organisasi. Penelitian ini bertujuan untuk menganalisis hubungan karakteristik individu, budaya organisasi organization citizenship behavior (OCB) dengan kinerja organisasi/perusahaan. Metode penelitian yang digunakan adalah kuantitatif explanatori dengan menggunakan 35 responden karyawan dalam bidang jasa konsultasi keuangan di kota Surabaya.

Analisis penelitian membuktikan bahwa ada hubungan secara langsung maupun tidak langsung antara karakteristik individu, budaya organisasi, organization citizenship behavior (OCB) dengan kinerja organisasi. Hasil analisis membuktikan bahwa hanya budaya organisasi dan organization citizenship behavior (OCB) yang memberikan hubungan secara langsung dan signifikan dengan kinerja organisasi, sedangkan karakteristik individu tidak memberikan korelasi secara langsung dengan kinerja organisasi.
\end{abstract}

Kata kunci: Karakteristik individu, Budaya organisasi, organization citizenship behavior (OCB), Kinerja organisasi. 


\section{PENDAHULUAN}

Banyak faktor yang memengaruhi kinerja suatu organisasi, begitu pula perbedaan organisasi misalnya organisasi bisnis, organisasi publik, organisasi sosial, organisasi kemasyarakatan dan lain sebagaianya. Kinerja organisasi selalu berkaitan dengan sumber daya manusia sebagai faktor pelaksana kegiatan dan aktivitas di dalamnya. Kinerja organisasi (perusahaan) adalah pencapaian atas tujuan organisasi yang dapat berbentuk output kuantitatif maupun kualitatif, kreativitas, fleksibilitas perusahaan (Purwanto, 2013). Kinerja perusahaan atau kinerja organisasi bisnis dapat pula diukur melalui prestasi perusahaan yang telah dicapai serta target yang telah ditentukan oleh para pemilik perusahaan. Manajemen perusahaan merupakan pihak yang paling bertanggung jawab terhadap pencapaian tersebut. Keterampilan menejerial pimpinan perusahaan merupakan kunci utama dan cermin dari kinerja perusahaan (Thoyib, 2005).

Individu sebagai bagian anggota organisasi/perusahaan memberikan kontribusi yang sangat signifikan dalam memberikan warna dan dinamika dalam perkembangan dan peningkatan kinerja organisasi. Karakteristik individu akan mempengaruhi sikap dan perilaku individu dalam melaksanakan tugas dan fungsinya dalam berorganisasi. Daya adaptasi individu yang baru masuk dan yang sudah lama berada dalam organisasi juga mempunyai hubungan dengan karakteristik individu, dimana individu yang berada dalam organisasi harus menghadapi budaya-budaya yang sudah ada dan berlaku di dalam organisasi tersebut.

Budaya perusahaan merupakan sistem nilai, kepercayaan dan kebiasaan yang menjadi dasar karyawan dan seluruh elemen perusahaan untuk beraktivitas dan berkegiatan dalam mencapai tujuan perusahaan. Budaya perusahaan akan menjiwai semua perilaku karyawan dalam bekerja, perkembangan dan pertumbuhan budaya perusahaan menyebabkan dan berhubungan dengan kinerja perusahaan (Nawawi Uha, 2013). Budaya organisasi merupakan pedoman bagi anggota organisasi dalam bertindak dan bertingkah laku, berhubungan, berkomunikasi serta berkerja sebagai individu ataupun kelompok.

Konsekuensi adanya budaya organisasi akan berdampak pada terbentuknya organizational citizenship behavior (OCB) sebagai perwujudan nyata adanya aktifitas budaya organisasi. OCB merupakan suatu perilaku positif individu sebagai anggota organisasi dalam bentuk kesediaan secara sadar dan sukarela untuk bekerja dan memberikan kontribusi pada organisasi lebih daripada apa yang dituntut secara formal dalam organisasi. OCB ini memiliki peran penting untuk keberhasilan organisasi. Organizational Citizenship Behavior (OCB) merupakan perilaku pilihan yang tidak menjadi bagian dari kewajiban kerja formal seorang karyawan, namun mendukung berfungsinya organisasi tersebut secara efektif. Tujuan dari penelitian ini adalah menganalisis hubungan antara karakteristik individu, budaya organisasi dan organizational citizenship behavior (OCB) dengan kinerja organisasi.

\section{LANDASAN TEORI}

Organisasi merupakan kumpulan dari individu-individu dimana masing-masing diantaranya mempunyai pribadi yang unik berkat latar belakang mereka, karakteristik individual, kebutuhan, dan cara mereka memandang dunia dan individu lain. Perbedaan individu membentuk perilaku organisasi, dan pada akhirnya keberhasilan individu dan organisasi. Perbedaan individu, misalnya membantu menjelaskan mengapa beberapa orang bersedia menerima perubahan dan beberapa yang lain merasa 
Arie, Hubungan Karakteristik Pribadi Individu, Budaya Organisasi, ....

takut terhadap perubahan. Juga menjelaskan mengapa beberapa karyawan hanya produktif ketika mereka diawasi dengan ketat, sementara yang lainnya lebih produktif ketika mereka tidak diawasi. Atau mengapa beberapa orang mempelajari tugas baru lebih efektif dari yang lainnya. Semua aktivitas organisasi selalu dipengaruhi oleh perbedaan individu (Akbar, 2009). Individu-individu dalam organisasi dalam bertindak dan berperilaku juga tidak lepas dari tujuan mereka sebagai anggota organisasi. Tujuan adalah keadaan masa depan yang dicoba hendak dicapai oleh seorang individu, dimana tujuan terdiri atas isi tujuan dan intensitas tujuan. Isi tujuan adalah sasaran atau hasil yang tengah diupayakan dan berubah-ubah dari yang spesifik sampai abstrak (Hoy \& Miskel, 2013).

Defenisi mengenai budaya organisasi yang ada saat ini sudah cukup banyak dan begitu beragam dan tergantung dari mana kita melihatnya. Budaya organisasi merupakan perangkat sosial yang mengikat anggota-anggota organisasi secara bersamasama melalui nilai-nilai bersama, normanorma standar yang jelas tentang apa yang dapat dan tidak dapat dilakukan dan dikatakan oleh anggotanya. Kreitner dan Kinicki (2005) dalam (Ambarwati, 2018) mengemukakan bahwa budaya organisasi adalah satu wujud anggapan yang dimiliki, diterima secara implisit oleh kelompok dan menentukan bagaimana kelompok tersebut rasakan, pikirkan dan bereaksi terhadap lingkungannya yang beraneka ragam. Hal ini diasumsikan, diciptakan, ditemukan atau dikembangkan oleh kelompok tertentu karena adanya proses pemahaman untuk mengatasi masalah eksternal dan integrasi internal yang dianggap valid dan karena itu harus diajarkan kepada anggota baru sebagai suatu cara yang benar untuk memahami, berpikir dan merasa sebagai bagian dari organsiasi (Schein, 2010).

Konsep Organizational Citizenship Behavior didefinisikan oleh MacKenzie
(2005) sebagai perilaku individu yang tergantung kepada kebijaksanaan individu tersebut, tidak secara langsung atau eksplisit dikenal oleh sistem penghargaan formal, dan hal itu secara agregat menghasilkan fungsi efektif bagi organisasi (Ariani, 2014). Organizational Citizenship Behavior (OCB) telah diteliti menjadi faktor penting dalam efektifitas organisasi. OCB adalah perilaku yang ditunjukkan karyawan melebihi deskripsi dari pekerjaannya (Ruiz-Palomino \& Martínez-Cañas, 2014). ). Dampak OCB diantaranya peningkatan efektifitas organisasi, kesadaran inovasi, serta kemampuan individu beradaptasi dalam berbagai organisasi. Podsakoff dkk dalam (Joo, 2011) menyatakan bahwa dari waktu ke waktu dan persaingan dalam perusahaan, OCB menjadi penting untuk membantu pencapaian tujuan organisasi sehingga dapat meningkatkan kinerja organisasi. Karena masing-masing individu mempunyai pengharapan berbeda dalam sebuah organisasi, sehingga organisasi harus mengetahui kebutuhan dari karyawannya agar setiap karyawan mampu menunjukkan hasil kerja yang maksimal.

Kinerja organisasi atau kinerja perusahaan merupakan indikator tingkatan prestasi yang dapat dicapai dan mencerminkan keberhasilan manajer/pengusaha. Kinerja merupakan hasil yang dicapai dari perilaku anggota organisasi (Shahzad, Adeel Luqman, Rashid Khan, \& Shabbir, 2012). Jadi kinerja organisasi merupakan hasil yang diinginkan organisasi dari perilaku orang-orang di dalamnya. Penilaian kinerja organisasi dapat ditinjau dari rasio keuangan perusahaan. Menurut Muthike (2016) profitabilitas merupakan ukuran keberhasilan operasi perusahaan. Perusahaan dikatakan mempunyai keunggulan bersaing apabila mempunyai tingkat laba yang tinggi dari rata-rata tingkat laba normal. Namun pada pertengahan dekade tahun 1990-an penggunaan tolok ukur finansial semakin tidak mendapatkan 
pengikut dengan semakin terkuaknya kelemahan mendasar tolok ukur tersebut. Kaplan dan Norton (2009) mengembangkan tolok ukur keberhasilan perusahaan yang lebih komprehensif, dinamakan Balanced Scorecard (BS).

Menurut konsep balanced scorecard kinerja perusahaan untuk mencapai keberhasilan kompetitif dapat dilihat dari empat bidang yaitu berdasarkan (1) Perspektif finansial, dimana pada perspektif ini perusahaan dituntut untuk meningkatkan pangsa pasar, peningkatan penerimaan melalui penjualan produk perusahaan; (2) Perspektif pelanggan, dimana perusahaan harus mengidentifikasi kebutuhan pelanggan dan segmen pasar; (3) Perspektif proses bisnis internal, dimana perusahaan harus mengidentifikasi proses-proses yang paling kritis untuk mencapai tujuan peningkatan nilai bagi pelanggan (perspektif pelanggan) dan tujuan peningkatan nilai finansial; (4) Perspektif pertumbuhan dan pembelajaran, dimana tujuan-tujuan yang ditetapkan dalam perspektif finansial, pelanggan dan proses bisnis internal mengidentifikasi dalam organisasi harus unggul untuk mencapai terobosan kinerja, sementara tujuan dalam perspektif pembelajaran dan pertumbuhan memberikan infrastruktur yang memungkinkan tujuan-tujuan ambisius dalam ketiga perspektif itu tercapai. Tujuantujuan dalam perspektif ini merupakan pengendali untuk mencapai keunggulan outcome ketiga perspektif sebelumnya.

\section{METODE PENELITIAN}

Sesuai dengan tujuan penelitian, yaitu untuk menguji dan menganalisis hubungan variabel independen terhadap variabel dependen maka jenis penelitian yang digunakan adalah jenis penelitian eksplanatoris. Penentuan jenis penelitian eksplanatoris ini sesuai dengan pengertian yang dijelaskan oleh (Silalahi, 2017), yaitu penelitian yang dilakukan dengan maksud penjelasan (explanatory atau confirmatory) yang memberikan penjelasan kausal atau hubungan antar variabel melalui pengujian hipotesis. Penelitian penjelasan adalah untuk menguji hubungan antar variabel yang dihipotesiskan. Pengujian hipotesis dengan analisis jalur (path analyze) untuk menentukan pengaruh antara variabel. Populasi dan sampel yang digunakan dalam penelitian ini adalah karyawan yang bekerja di bidang jasa konsultan keuangan yang ada di kota Surabaya. Sebanyak 35 responden direkrut dalam penelitian ini. Adapun kerangka konseptual dapat ditunjukkan pada gambar 1.

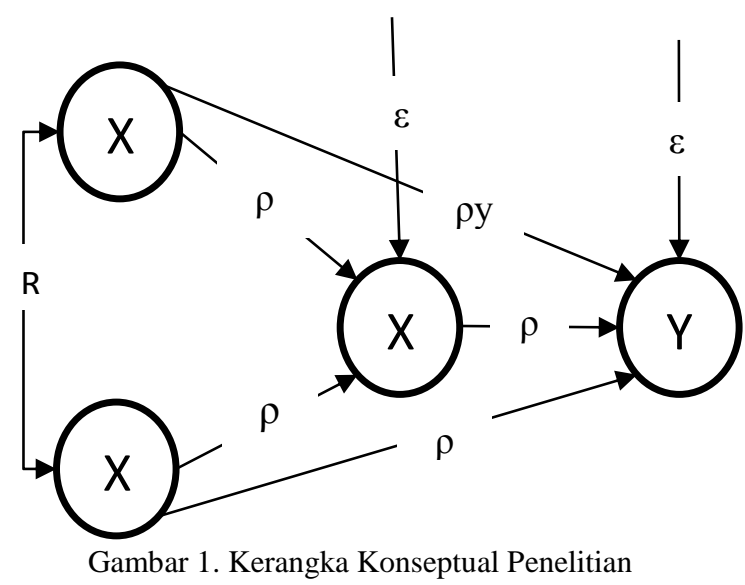

Keterangan:

$\mathrm{X} 1$ = Karakteristik Individu

$\mathrm{X} 2$ = Budaya Organisasi

$\mathrm{X} 3$ = Organization Citizenship Behavior

$\mathrm{Y}=$ Kinerja Organisasi

Definisi Operasional Variabel

Adapun definisi operasional dan pengukuran masing-masing variabel penelitian adalah sebagai berikut :

1. Karakteristik Individu $\left(\mathrm{X}_{1}\right)$

Karakteristik individu diukur dari persepsi karyawan yang terdiri dari beberapa indikator sebagai berikut : (a) Minat;dikarakteristikkan dengan pemahaman tentang pekerjaan, kesiapan, dan semangat kerja; (b) Sikap, ditandai 
Arie, Hubungan Karakteristik Pribadi Individu, Budaya Organisasi, ....

oleh karakteristik kepribadian dan control diri; (c) Kemampuan, diukur melalui pelaksanaan tugas, ketepatan waktu dan keterampilan dalam mengatasi pekerjaan; dan (d) Kebutuhan, diukur melalui kebutuhan akan berprestasi dan kejelasan.

2. Budaya organisi $\left(\mathrm{X}_{2}\right)$ diukur dengan menggunakan indikator sebagai berikut :(a) Inovasi dan keberanian mengambil resiko, dipersepsikan seberapa jauh karyawan berani melakukan inovasi dan mengambil resiko dalam inovasinya; (b) Perhatian pada detail, di mana karyawan dapat melakukan analisis dan persisi pada tugas dan pekerjaannya; (c) Berorientasi pada hasil, sebagaimana perusahaan maka orientasi hasil adalah tujuan utama; (d) Berorientasi pada manusia, parameter yang digunakan adalah dampak keputusan-keputusan yang dihasilkan akan berpengaruh pada manusia sebagai anggota organisas; (e ) Berorientasi pada tim, pengukuran dilakukan dengan mengukur kinerja tim dalam organisasi; (f) Agresivitas, merupakan penentuan tingkat sikap agresif dan kompetitif dibandingkan bersantai; (g) Stabilitas, yaitu sejauh mana kegiatan-kegiatan organisasi dipertahankan status quo.

3. Organization Citizenship Behavior $\left(\mathrm{X}_{3}\right)$ diukur dengan menggunakan indikator sebagai berikut: (a) Altruisme (Altruism) merupakan perilaku menolong, memberikan bantuan di luar tugas kewajiban pokok pekerjaan dengan sukarela baik yang berhubungan dengan pekerjaan maupun diluar pekerjaan; (b) Kesopanan (Courtesy) yaitu mencegah timbulnya masalah dengan orang lain dan perusahaan, yang ditunjukkan dengan rasa saling menghormati, perhatian, serta menghargai rekan kerja; (c) Kesadaran (Conscientiousness) merupakan perilaku optimis terhadap pekerjaan, dengan mentaati peraturan dalam pekerjaan serta menjalankan apa yang telah ditugaskan kepadanya atau perilaku yang menunjukkan sebuah usaha agar melebihi harapan dari organisasi; (d) Sportif (Sportmanship). Toleransi terhadap gangguan pada pekerjaan atau menghilangkan perasaan negative seperti tidak mengeluh dan berusaha merasa nyaman dengan pekerjaan; dan (e) Tanggung jawab (Civic Virtue). yaitu menunjukkan rasa tanggung jawab dan kepedulian atas kelangsungan perusahaan atau organisasi (Ambarwati, 2019).

4. Kinerja Organisasi dikukur dengan indikator: (a) Financial perspective merupakan kemampuan yang dicapai oleh organisasi dalam mewujudkan visinya; (b) Customer perspective merupakan memberikan gambaran segmen pasar yang dituju dan pelanggan beserta tuntutan kebutuhan yang dilayani oleh organisasi dalam upaya untuk mencapai sasaran keuangan tertentu; (c) Internal and Proses Business Perspective merupakan gambaran proses yang harus dibangun untuk melayani pelanggan dan untuk mencapai sasaran keuangan tertentu; serta (d) Learning and Growth perspective, merupakan pemacu untuk membangun kompetensi personel, pra sarana sistem informasi dan suasana lingkungan kerja yang diperlukan untuk mewujudkan sasaran keuangan, pelanggan, proses bisnis internal (Ambarwati, 2018).

ANALISIS HASIL DAN PEMBAHASAN Hasil analisis dengan menggunakan SPSS 24 ditunjukkan dalam beberapa tabel hasil interpretasi dari output perhitungan statistika. Berdasarkan kerangka konseptual diatas maka model analisis jalur dilakukan melalui dua substruktur dengan hipotesis penelitian sebagai berikut:

1. Keterlibatan karyawan dan desain pekerjaan berkontribusi secara simultan dan signifikan terhadap Organization citizenship behavior. 
Journal of Applied Business Administration Vol 3, No 1, Maret 2019, hlm. 111-118.

2. Keterlibatan, desain pekerjaan, dan organization citizenship behavior berkontribusi secara simultan dan sifnifikan terhadap kinerja organisasi.

Tabel 1. Analisis of Varians Model 1 dan 2

\begin{tabular}{|c|c|c|c|c|c|}
\hline Model & $\begin{array}{c}\text { Sum of } \\
\text { Square } \\
\text { s }\end{array}$ & $\begin{array}{l}\text { d } \\
\mathbf{f}\end{array}$ & $\begin{array}{c}\text { Mean } \\
\text { Squar } \\
\text { e }\end{array}$ & $\mathbf{F}$ & $\begin{array}{c}\text { Sig } \\
\text { • }\end{array}$ \\
\hline $\begin{array}{l}\text { 1. Regressi } \\
\text { on } \\
\text { Residual } \\
\text { Total }\end{array}$ & $\begin{array}{c}1866,27 \\
8 \\
63,389 \\
1929,66 \\
7\end{array}$ & $\begin{array}{l}8 \\
1 \\
1\end{array}$ & $\begin{array}{c}622,09 \\
3 \\
7,924\end{array}$ & $\begin{array}{c}78,51 \\
1\end{array}$ & $\begin{array}{c}.00 \\
0\end{array}$ \\
\hline $\begin{array}{l}\text { 2. Regressi } \\
\text { on } \\
\text { Residual } \\
\text { Total }\end{array}$ & $\begin{array}{c}1845,47 \\
6 \\
84,190 \\
1929,66 \\
7\end{array}$ & $\begin{array}{l}9 \\
1 \\
1\end{array}$ & $\begin{array}{c}922,73 \\
8 \\
9,354\end{array}$ & $\begin{array}{c}98,64 \\
1\end{array}$ & $\begin{array}{c}.00 \\
0\end{array}$ \\
\hline
\end{tabular}

a. Predictors: (constant), Organization citizenship behavior $\left(\mathrm{X}_{3}\right)$, Karakteristik individu $\left(\mathrm{X}_{2}\right)$, budaya organisasi $\left(\mathrm{X}_{1}\right)$

b. Dependent variable: Kinerja Organisasi (Y)

Tabel 2. Koefisien Variabel Model 1 dan 2

\begin{tabular}{|c|c|c|c|c|c|}
\hline \multirow{2}{*}{ Model } & \multicolumn{2}{|c|}{$\begin{array}{l}\text { Unstandardi } \\
\text { zed } \\
\text { Coefficients }\end{array}$} & \multirow{2}{*}{$\begin{array}{c}\begin{array}{c}\text { Standa } \\
\text { rdized } \\
\text { Coeffic } \\
\text { ients }\end{array} \\
\text { Beta }\end{array}$} & \multirow[t]{2}{*}{$\mathbf{t}$} & \multirow[t]{2}{*}{ Sig. } \\
\hline & B & $\begin{array}{c}\text { Std. } \\
\text { Err } \\
\text { or }\end{array}$ & & & \\
\hline $\begin{array}{l}\text { 1. (const } \\
\text { ant) }\end{array}$ & 1,062 & $\begin{array}{c}4,61 \\
9\end{array}$ & & 0,230 & 0,824 \\
\hline $\begin{array}{l}\text { Karaterist } \\
\text { ik } \\
\text { individu } \\
\left(\mathrm{X}_{1}\right)\end{array}$ & $\begin{array}{c}- \\
0,198\end{array}$ & $\begin{array}{c}0,12 \\
2\end{array}$ & $-0,228$ & $\begin{array}{c}- \\
1,620\end{array}$ & 0,144 \\
\hline $\begin{array}{l}\text { Budaya } \\
\text { Organisa } \\
\text { si }\left(\mathrm{X}_{2}\right)\end{array}$ & 0,599 & $\begin{array}{c}0,09 \\
5\end{array}$ & 0,641 & 6,297 & 0,000 \\
\hline $\begin{array}{l}O C B \\
\left(\mathrm{X}_{3}\right) \\
\end{array}$ & 0,777 & $\begin{array}{c}0,22 \\
4 \\
\end{array}$ & 0,588 & 3,470 & 0,008 \\
\hline $\begin{array}{l}\text { 2.(consta } \\
\text { nt) }\end{array}$ & 3,514 & $\begin{array}{c}4,74 \\
2\end{array}$ & & 0,741 & 0,478 \\
\hline Budaya & 0,622 & 0,10 & 0,666 & 6,087 & 0,000 \\
\hline $\begin{array}{l}\text { Organisa } \\
\text { si }\left(X_{2}\right)\end{array}$ & & 2 & & & \\
\hline $\begin{array}{l}O C B \\
\left(\mathrm{X}_{3}\right)\end{array}$ & 0,485 & $\begin{array}{c}0,14 \\
5\end{array}$ & 0,367 & 3,357 & 0,008 \\
\hline
\end{tabular}

a. Dependent variabel: Kinerja Organisasi (Y)
Tabel 3. Summary Model 1 dan 2

\begin{tabular}{|c|c|c|c|c|}
\hline Model & $\mathbf{R}$ & $\begin{array}{c}\text { R } \\
\text { Square }\end{array}$ & $\begin{array}{c}\text { Adjusted } \\
\text { R Square }\end{array}$ & $\begin{array}{c}\text { Std.E } \\
\text { rror } \\
\text { of the } \\
\text { Estim } \\
\text { ate }\end{array}$ \\
\hline 1 & 0,983 & 0,967 & 0,955 & 2,815 \\
\hline 2 & 0,987 & 0,956 & 0,947 & 3,059 \\
\hline
\end{tabular}

a. Predictors: (Constant), OCB $\left(\mathrm{X}_{3}\right)$, budaya organisasi $\left(\mathrm{X}_{2}\right)$, Karakteristik individu $\left(\mathrm{X}_{1}\right)$

b. Dependent variable: Kinerja Organisasi (Y) Berdasarkan hasil analisis ulang jalur 2 (substruktur 2) model 2 pada tabel 3 diatas dapat dijelaskan bahwa:

$\checkmark$ y x $_{2}=$ beta $=0,666[\mathrm{t}=6,087$ dan probabilitas sig $=0,000]$

$\checkmark \operatorname{pyx}_{3}=$ beta $=0,367 \quad[\mathrm{t}=3,357$ dan probabilitas sig $=0,008]$

Besarnya koefisien diterminansi (kontribusi) $\mathrm{X}_{1}$ dan $\mathrm{X}_{3}$ secara simultan terhadap $\mathrm{Y}$ sebesar $\left(\mathrm{R}_{\text {square }}=\mathbf{R}_{\text {YX3X1 }}^{2}\right)=($ pyx1).(ryx1) + (рух3).(ryx3)

$\mathbf{R}_{\mathbf{y \times 3 \times 2}}^{2}=(0,666)(0,950)+(0,367)(0,881)$

$\mathbf{R}_{\mathbf{y} \times 3 \times 2}^{2}=(0,6327)+(0,3233)$

$\mathbf{R}_{\mathbf{y x 3 \times 2}}^{\mathbf{2}}=0,956$ (lihat tabel 2) dan besar koefisien residu untuk $\rho_{\mathrm{y}} \varepsilon_{2}=\sqrt{1-0,956}=0,2098$.

Hasil koefisien jalur pada sub-struktur 1 dan substruktur 2 berubah menjadi persamaan struktur yaitu:

$\mathrm{X}_{3}=\rho_{\mathrm{x} 3 \mathrm{x} 2} \mathrm{X}_{\mathbf{2}}+\rho_{\mathrm{x} 3} \varepsilon_{1}$ dan $\mathrm{R}_{\mathrm{x} 3 \mathrm{x} \mathbf{1}}^{2}$

$\mathbf{X}_{\mathbf{3}}=0,887 \mathbf{X}_{2}+0,4615 \varepsilon_{1}$ dan 0,787

$\mathbf{Y}=\boldsymbol{\rho}_{\mathrm{yx} \mathbf{1}} X_{\mathbf{2}}+\boldsymbol{\rho}_{\mathrm{yx} \mathbf{3}} X_{\mathbf{3}}+\boldsymbol{\rho}_{\mathrm{y}} \varepsilon_{\mathbf{2}}$ dan $\mathbf{R}_{\mathrm{yx} \mathbf{3} \mathbf{x} \mathbf{1}}^{\mathbf{2}}$

$\mathbf{Y}=0,666 \mathbf{X}_{2}+0,367 \mathrm{X}_{3}+0,2098 \varepsilon_{2}$ dan 0,956

\section{Memaknai Hasil Analisis Jalur}

Berdasarkan hasil perhitungan secara keseluruhan, maka dapat dimaknai dan dibahas serta memberikan informasi secara objektif sebagai berikut:

1. Hipotesis pertama "Karakteristik individu dan budaya organisasi berhubungan secara langsung dan signifikan dengan OCB”. 
Arie, Hubungan Karakteristik Pribadi Individu, Budaya Organisasi, ....

Membuktikan tidak semua variabel dapat diterima, di mana pada koefisien jalur 2 (sub-struktur 2) hanya koefisien budaya organisasi yang berhubungan secara langsung dan signifikan terhadap OCB. Besarnya hubungan langsung dan signifikan budaya organisasi dengan OCB sebesar $0,887^{2} \times 100 \%=78,68 \%$ dan sisanya $0,4615^{2} \times 100 \%=21,3 \%$ merupakan kontribusi dari variabel lain di luar variabel budaya organisasi.

2. Hipotesis kedua "Karakteristik individu, budaya organisasi dan OCB berhubungan secara langsung dan signifikan terhadap kinerja organisasi". Membuktikan budaya organisasi dan OCB berhubungan secara langsung dan signifikan dengan kinerja organisasi, di mana besarnya sebagai berikut:

a. Besarnya hubungan secara langsung budaya organisasi dengan kinerja organisasi adalah $0,666^{2} \times 100 \%=$ $44,36 \%$.

b. Besarnya hubungan OCB yang secara langsung signifikan dengan kinerja organisasi adalah $0,367^{2} \times 100 \%=$ $13,47 \%$

c. Besarnya hubungan budaya organisasi dan OCB secara langsung dan signifikan dengan kinerja organisasi adalah $0,956=95,6 \%$ dan sisanya sebesar $0,2098^{2}$ x $100 \%=4,4 \%$ dipengaruhi faktor - faktor lain yang tidak dapat dijelaskan dalam penelitian ini.

3. Hubungan tidak langsung karakteristik individu dengan kinerja organisasi melalui OCB adalah $(0,897) .(0,367)=0,329$ dengan demikian hubungan langsung total karakteristik individu dengan prestasi kerja sebesar 0,329.

Berdasarkan analisis diatas akan membuktikan bahwa budaya organisasi dan Organization citizenship behavior (OCB) mempunyai hubungan secara langsung dan signifikan terhadap kinerja organisasi, sedangkan karakteristik individu merupakan variabel penelitian yang tidak memberikan hubungan secara langsung terhadap kinerja organisasi. Untuk dapat memberikan kontribusi yang optimal terhadap kinerja organisasi maka karakteristik individu harus melalui budaya organisasi Organization citizenship behavior (OCB).

\section{SIMPULAN}

Karakteristik individu dan budaya organisasi mempunyai hubungan secara langsung kepada organization citizenship behavior (OCB). Dalam mewujudkan OCB yang kondusif maka manager harus senantiasa memperhatikan karakteristik individu karyawannya dalam setiap pengambilan keputusan bagi kesejahteraan karyawannya. Budaya organisasi akan memberikan rasa nyaman serta membangun atmosfer bekerja yang konduksif bagi karyawan sehingga karyawan akan memberikan seluruh kemampuannya dalam bekerja untuk memberikan dan membuktikan keterampilannya kepada organisasi/perusahaan.

Budaya dan organization citizenship behavior (OCB) mempunyai hubungan secara langsung dan signifikan dengan kinerja organisasi/perusahaan. Hal ini adalah merupakan masukan kepada manager/pimpinan organisasi/perusahaan untuk senantiasa mempertimbangkan keberadaan budaya organisasi/perusahaan dan pertumbuhan organization citizenship behavior (OCB) sebagai upaya untuk meningkatkan kinerja organisasi/perusahaan. Faktor lain yang tidak kalah penting adalah dengan memperhatikan dan mempertimbangkan karakteristik individu yang disesuaikan dengan kompetensi dan kemampuan karyawan ketika menempatkan seorang pekerja pada tempat yang sesuai untuk dapat mengembangkan potensinya.

\section{REFERENSI}

Akbar, A. (2009). Pengaruh Karakteristik Pekerjaan, Karakteristik Organisasi, dan Karakteristik Individu Terhadap Kepuasan Kerja Karyawan Bank Swasta di Propinsi Sulawesi Selatan. ISSN 0852, 8144(6), 183-192. Retrieved from http://pasca.unhas.ac.id/jurnal/files/e3fe857 ee1cc0eeb73bbbd4cfa2944bf.pdf 
Ambarwati, A. (2018). Perilaku dan Teori Organisasi. (Amirullah, Ed.), Media Nusa Creative (Pertama). Malang: Media Nusa Creative. https://doi.org/10.1111/j.14690691.2011.03558.x/pdf

Ambarwati, A. (2019). Kontribusi Keterlibatan Karyawan Dan Desain Pekerjaan Terhadap Organization Citizenship Behavior Sert A Kinerja Organisasi. Jurnal Akademika, 17(1), 15-21.

Ariani, D. W. (2014). Relationship Leadership, Employee Engagement, and Organizational Citizenship Behavior. International Journal of Business and Social Research, 4(8), 74-90. Retrieved from

http://thejournalofbusiness.org/index.php/si te/article/view/589

Hoy, W. K., \& Miskel, C. G. (2013). Educational Administration, Theory, Research and Practice 9th Edition. New Jersey: McGraw Hill Inc.

Joo, B.-K. (2011). Knowledge Sharing: The Influences of Learning Organization Culture, Organizational Commitment, and Organizational Citizenship Behaviors. Journal of Leadership \& Organizational Studies, 18(3), 353-364. https://doi.org/10.1177/1548051811405208

Kaplan, R. S. (2009). Conceptual foundations of the balanced scorecard. Handbooks of Management Accounting Research, 3, 1253-1269.

Muthike, C. (2016). The Impact of Employee Engagement on Organization Performance: A Case of Pact, Nairobi. Retrieved from http://erepo.usiu.ac.ke/handle/11732/3161

Nawawi Uha, I. (2013). Budaya Organisasi, Kepemimpinan, Dan Kinerja Proses Terbentuk, Tumbuh Kembang, Dinamika, Dan Kinerja Organisasi (Kesatu). Jakarta: Kencana Prenadamedia Grup.

Purwanto, A. (2013). Variabel Anteseden Budaya Organisasi dan Pengaruh Strategi Bisnis terhadap Kinerja Organisasi: Pendekatan Konsep. Jurnal Akuntansi Aktual, 2(1).

Ruiz-Palomino, P., \& Martínez-Cañas, R. (2014). Ethical Culture, Ethical Intent, and Organizational Citizenship Behavior: The Moderating and Mediating Role of Person-
Organization Fit. Journal of Business

Ethics, 120(1), 95-108. https://doi.org/10.1007/s10551-013-1650-1

Schein, E. H. (2010). Organizational Culture and Leadership. John Wiley \& Sons. Retrieved from https://books.google.co.id/books?id=kZH6 AwTwZV8C

Shahzad, F., Adeel Luqman, R., Rashid Khan, A., \& Shabbir, L. (2012). Impact of organizational culture on organizational performance: An overview. Interdisciplinary Journal of Contemporary Research in Business, 3(9), 975-985. Retrieved from ijcrb.webs.com

Silalahi, U. (2017). Metode Penelitian Sosial Kuantitatif. Bandung: PT Refika Aditama.

Thoyib, A. (2005). Hubungan kepemimpinan, budaya, strategi, dan kinerja: pendekatan konsep. Jurnal Manajemen Dan Kewirausahaan (Journal of Management and Entrepreneurship), 7(1), 60-73. https://doi.org/10.9744/jmk.7.1.pp. 60-73 